\title{
UN COMENTARIO SOBRe LA POESÍA DEL EXILIO DEL CONDE DE VILLAMEDIANA. "AL RETIRO DE LAS AMBI- CIONES DE LA CORTE"
}

\author{
Juan MATAS CABALLERO \\ Universidad deLeón
}

No se puede seguir manteniendo el marbete de poeta menor por más tiempo cuando se habla de poetas como Pedro Soto de Rojas, Juan de Arguijo, Pedro Espinosa, Francisco de Rioja, Juan de Jáuregui o, entre otros muchos más nombres, Juan de Tassis, el Conde de Villamediana. El paso de los siglos debe comportarse con su obra, quizás, con más benevolencia que la gozada por sus autores mientras vivieron, siempre a la sombra de indiscutibles figuras de fuste y merecido relumbrón poético (Luis de Góngora, Lope de Vega, Francisco de Quevedo). Sería impropio e injusto ponderar ahora la elevada calidad literaria de la obra de aquellos poetas que tradicional mente han venido siendo postergados por la historiografía crítico-literaria.

Ya no hay, pues, quien dude de su elevada categoría estética y, por lo tanto, hay que tratarlos, cuando su obra así lo merezca, en el mismo plano de igualdad en que se tiene a las indiscutidas primeras plumas del Siglo de Oro. Éste es el caso del Conde de Villamediana, cuya poesía merece estar, a mi juicio, entre las mejores obras del vasto y excelente panorama de nuestra poesía áurea. Por ello quiero sumar mi esfuerzo al de aquellos estudiosos que -con diferente perspectiva crítica- han intentado subrayar el significado y el valor literario de su poesía anal izando no pocos de los distintos elementos que la singularizan ${ }^{1}$.

Las relaciones entre vida y literatura casi siempre han terminado por hacer un flaco favor al cabal y óptimo conocimiento de la segunda, que suele acabar relegada por el ruidoso ajetreo de la primera. De hecho, es habitual la confusión que se suele producir entre la literatura y la vida literaria. Si bien es cierto que este fenómeno es más contemporáneo, más propio de nuestro tiempo, sobre todo por el extraordinario desarrollo de los medios de comunicación, y la consecuente y desmesurada atención que éstos prestan a la vida literaria, la verdad es que esta contaminación entre la literatura y la vida literaria se ha producido siempre, incluso en nuestra Edad de Oro. Y lo peor de todo, en cualquier época de la historia literaria, se produce cuando se confunde lo verdaderamente literario (la obra literaria en sí) con lo pseudoliterario, es decir, la vida literaria o todo lo que rodea a la obra escrita, pero que resulta, en definitiva, totalmente ajeno a ella, por cuanto que nada aporta a su mejor estudio y conocimiento. Cuando la crítica literaria termina bajo esa mixtura de criterios y cruza indistintamente las fronteras de lo literario y de lo pseudoliterario, los resultados no pueden ser más

${ }^{1}$ Al final de este trabajo se consignan algunos de los trabajos más relevantes realizados sobre Villamediana y que han sido de gran utilidad para la redacción de estas páginas. 
desoladores, por su gran dosis de simpleza, confusión e, incluso, error. Así, por poner tan sólo un ejemplo, se pone de manifiesto cuando las rivalidades personales entre Góngora y Quevedo, aunque ciertas, fueron increíblemente exageradas y extrapoladas al terreno de la crítica literaria, y terminaron convertidas en dos posturas estilísticas diferentes y antagónicas que se sustanciaron, respectivamente, en la dicotomía culteranismo y conceptismo².

Algo similar ha sido lo ocurrido con el Conde de Villamediana, cuya vida fue tan intensa y atractiva que atrajo casi toda la atención de la crítica literaria hasta el punto de terminar, por un lado, dejando casi en penumbra su propia obra literaria y, por otro, fantaseando de forma exagerada hasta inventar -más que documentar- sus avatares vitales, toda una peripecia que inicia su deformante trayectoria ya desde los tiempos del malogrado poeta. Así pues, si la excesiva atención que la crítica ha prestado a la vida de Villamediana ha perjudicado sobremanera a su obra, que ha quedado notablemente postergada, parece obvio que debemos prestar cada vez más atención a su poesía, y eso es lo que pretendo al comentar el soneto "Al retiro de las ambiciones de la Corte":

\begin{abstract}
Si para malcontentos hay sagrado, dulce quietud del ánimo lo sea en esta soledad, donde granjea aviso y no fatigas el cuidado.
\end{abstract}

El metal en la lluvia desatado sobre ambiciosa mano lograr vea quien aun con los engaños lisonjea de sus áulicas pompas adulado.

Sirenas sean lisonja de su oído que, adulterando a la razón las llaves, cierren la puerta del mejor sentido.

Yo entre estas mansas ondas, a las aves, en canto ni adulado ni aprendido, deberé el desmentir fatigas graves ${ }^{3}$.

El tema desarrollado en el poema ha permitido a la crítica especializada aventurar una hipótesis sobre su localización en el conjunto de la obra de Villa-

\footnotetext{
${ }^{2}$ Esta simpleza crítica fue subrayada y censurada, entre otros críticos, por Orozco (1988: I 59-68), pero aún hoy podemos comprobar cómo pervive semejante dislate (Ruiz 1996: 76-79). Sobre la cuestión podría consultarse una extensa nómina de interesantes trabajos, pero remito tan sólo al estudio de Mercedes Blanco (1992) porque resulta absolutamente esclarecedor.

${ }^{3}$ El soneto se ha transcrito siguiendo la edición que de la poesía de Villamediana ha realizado Rozas (19802: 299), cuyos estudios sobre la obra poética y la figura del Conde de Villamediana lo siguen avalando como su crítico más autorizado.
} 
mediana. Es sabido que el poeta fue desterrado en dos ocasiones: la primera, en 1608, fue desterrado de la corte como consecuencia de su afición y práctica del juego ${ }^{4}$, y la segunda, en 1618, por escribir sátiras contra los validos de Felipe III 5 . En pocos autores del Siglo de Oro como en Villamediana esa trágica experiencia se destiló con tanta intensidad y profusión en su obra literaria. Se podría afirmar que el exilio se ha convertido en un aspecto especialmente trascendente para explicar una parte importante de la poesía de Villamediana.

Hasta la fecha, la mejor clasificación, y más operativa, que se ha realizado de la poesía de Villamediana corresponde a su estudioso más autorizado, Rozas (19802: 16-17), quien la agrupó en cuatro núcleos: la poesía amorosa de raíz petrarquista (el mundo de Ícaro); la poesía declaradamente estética, de raíz gongorina y marinista; las fábulas mi tológicas (el mundo de Faetón); y la poesía vivencial de su interpretación moral del mundo, que tiene dos partes, los poemas morales y los satíricos (el mundo de Prometeo). Pues bien, el soneto que se comenta pertenece por el tema que trata al último grupo, al mundo de Prometeo, en el que se incluyen las composiciones morales y satíricas, que, según Rozas (ibidem, 18), podrían ser inscritas en el Cancionero del Desengaño, cuyo eje vivencial es el segundo destierro de Villamediana, y que cuenta con el que, a mi juicio, es el mejor poema que se ha escrito sobre el tema del destierro en la poesía española del Siglo de Oro: Silva que hizo el autor estando fuera de la Corte.

El soneto desarrolla el tema del alejamiento de las ambiciones y miserias de la corte -como recoge el propio título de la composición- y la opción personal por una soledad interior en un marco natural solitario e idílico en el que procurar la tranquillitas animi. Se trata, en realidad, de una composición que arranca de la larga tradición del menosprecio de corte y alabanza de aldea, aunque ofrece algunos matices que particularizan -como se verá- de forma significativa el texto de Villamediana.

El soneto adquiere tintes claramente personales, pues las circunstancias vitales del poeta están implícitas en el tema que se trata. En este caso concreto, la vida ha quedado literaturizada o, de otra forma, la literatura ha dado cobijo a la experiencia personal del poeta. De este modo, podría decirse que el tema de la soledad, del menosprecio de corte y alabanza de aldea o del beatus ille no sería sino una expresión literaria de la personal experiencia del exilio que ha vivido Villamediana.

El planteamiento del retiro de las ambiciones de la corte se debe de relacionar, a mi juicio, con el tema del exilio, aunque se trate de un exilio voluntario o autoexilio y no necesariamente del destierro al que se vio forzado el poeta. Según creo, Villamediana, en este soneto, ha logrado convertir la dura experiencia personal que representa el exilio no en un lastimoso canto por la desgracia pade-

\footnotetext{
${ }^{4}$ Sobre este destierro de Villamediana, véase Cotarelo (1886) y Rozas (1965: 37-40;1980²: 12-13).

${ }^{5}$ Este segundo destierro de Villamediana es más conocido gracias a la documentación existente; véase Muñoz de San Pedro (1946) y Rozas, ibidem.
} 
cida, sino en una circunstancia que le permite la elaboración de un discurso poé tico moral, siguiendo los pasos de aquellos que, desde la Antigüedad clásica, habían cincelado literariamente su desdichada experiencia del destierro, como, por ejemplo, Ovidio, Séneca o Plutarco. Este último, en su De exilio, termina elogiando la ausencia de política como al go positivo, pues esa experiencia le permite disfrutar del ocio, la libertad, llevar una vida tranquila y descansada dedicada a la reflexión moral (Guillén 1998: 32). Séneca, por su parte, supo transformar el tremendo castigo que suponía el exilio (al fin y al cabo, esa forma de muerte civil era una muerte en vida) en una oportunidad para demostrar la superación de las circunstancias adversas y subordinar esa contraria realidad exterior a la virtus interior, mientras se produce una feliz sintonía del individuo con la naturaleza. El exilio es, pues, una oportunidad para que el individuo se centre y sobrevalore la naturaleza y la virtud (Guillén 1998: 34-35). De esta manera, nuestro poeta se sitúa en la misma línea de argumentación de Plutarco, o los estoicos Séneca y Epicteto, entre otros, y el destierro -e, incluso, el autoexilio- representa una óptima ocasión para alejarse del enjambre de vicios y miserias humanas que es la Corte, como representación de la corrupta vida política, y volver los ojos hacia sí mismo, buscando la consecución del verdadero sentido de la razón, que no es otro que la virtud, sirviendo como principal elemento la soledad y la tranquilidad espiritual que se ve alimentado por un perfecto e idílico marco natural con el que el poeta se identifica.

Este poema de Villamediana apareció publicado en sus Obras (1629: 89) entre los Sonetos líricos. En la actualidad, lo podríamos considerar como un soneto moral, y como tal lo llamaron en la época del autor. Así, pues, esta composición puede encuadrarse dentro del género o subgénero de la poesía de tema moral. EI contenido íntimo del poema y el tema de claro fuste doctrinal y ético avalan la consideración de este soneto como poema lírico y moral. A lo largo del Siglo de Oro, el soneto fue experimentando tal desarrollo y ampliación de su materia poética que, aunque nos llegó como una forma poética apta para la poesía de contenido amoroso, sobre todo por venir de la mano del petrarquismo, a medida que se fue aclimatando y extendiéndose su uso, fue ensanchando sus límites hasta el punto de poder dar cabida a toda materia. Fernando de Herrera, que consideraba el soneto como "la más hermosa composición i de mayor artificio", ya certificaba su carácter polivalente en el tratamiento de cualquier asunto, pues era "capaz de todo argumento"6.

Puede decirse que, cuando Villamediana escribe o publica esta composición, el soneto ha dado acomodo a todo tipo de temas y a todas las modalidades o subgéneros poéticos, cualesquiera que fuera su contenido. Si bien es verdad que gran parte del corpus poético sonetil recrea el tema amoroso, no es menos cierto que en el cauce de los catorce versos se va a tratar prácticamente todo aquello que interesa al poeta, desde lo grave propio de la poesía reflexiva, de

\footnotetext{
${ }^{6}$ Fernando de Herrera, Anotaciones (2001: 265-66).
} 
contenido moral o ético, hasta lo más genuino de la poesía de corte satíricoburlesco. De esta forma, puede decirse que cualquier asunto puede ser tratado en el soneto que se ha convertido en esta época en un auténtico subgénero poético que es del gusto de todos los escritores y que representa la verdadera forja de los poetas, pues todos le terminaron rindiendo un especial tributo, por la variedad o por la cantidad con la que lo cultivaron.

En la primera estrofa el poeta se ve a sí mismo como un "malcontento"7, cuyo "sagrado" (que, metafóricamente, es, según Autoridades, "cual quier recurso o sitio que asegura de algún peligro, aunque no sea lugar sagrado") está en su "dulce quietud del ánimo" del lugar solitario en el que se halla, y cuya preocupación le proporciona "aviso y no fatigas".

El comienzo del poema nos sitúa, por supuesto, en la tradición horaciana del beatus ille, pero también se aprecia -como ha señalado Ruestes (1992: 106)- el recuerdo de Séneca (Ad Lucilium Ep. CIII, 4): “Quantum potes autem, in philosophiam recede: illa te sinu suo proteget, in huius sacrario eris aut tutus aut tutior". ${ }^{8} \mathrm{Y}$, como había señalado Vossler (1946: 324), a propósito de la Silva que hizo el autor estando fuera de la Corte, en este poema de Villamediana también se observa "la réplica cortesana de la mística quietista, que se extendía sobre el país como el tizón".

En otro orden de cosas, puede observarse cómo el hipérbaton al colocar "cuidado" al final de la proposición, siendo el sujeto de "granjea”, y la colocación al mismo tiempo al final del verso y de la estrofa, mientras que se sitúa el complemento directo "aviso" al principio del verso, se debe a la intención del poeta de subrayar cómo esa dulce soledad física y espiritual reporta al poeta lo positivo, el aviso, y no lo negativo, que serían las fatigas. De este modo, la construcción hiperbática contribuye a enfatizar la eficacia del mensaje ético.

Tras la primera estrofa en la que el poeta se ha situado en un primer plano mostrando su "dulce quietud del ánimo" como su particular sagrario, en la segunda, el poeta, a modo de contraste, fija su atención en lo que rechaza: las ambiciones y los engaños como botón de muestra de las miserias humanas y de las gloriae mundi de la corte.

El poeta cifra de forma simbólica en el poder del dinero y en la corte toda la corrupción en la que incurre el hombre en su tráfago social y político. La perífrasis mitológica sirve al poeta para referirse al oro y su enorme capacidad para lograr cuanto se propone. Según cuenta Ovidio (Metamorfosis IV 611), Júpiter se transformó en Iluvia de oro para conseguir la posesión amorosa de Dánae. Por eso el poeta, aludiendo de forma perifrástica a esa transformación de Júpiter, que le permitió lograr su propósito, se refiere al oro sin mencionarlo, y sin nombrar tampoco a ninguno de los dioses míticos implicados, con el fin de subrayar

${ }^{7}$ En la poesía del Siglo de Oro era frecuente el empleo de adjetivos compuestos con el adverbio "mal"; así, por ejemplo, Dámaso Alonso (1988: 90-91) ofrece numerosos ejemplos en la poesía de Francisco de Medrano.

${ }^{8}$ Cito por la edición de Séneca, Ad Lucilium Epistulae Morales (1971: 188). 
cómo el ambicioso puede conseguir con el dinero ver al que "lisonjea adulado con los engaños de sus áulicas pompas". A la censura y distanciamiento que el poeta manifiesta respecto del ambicioso, suma también su rechazo del adulador que engaña al tiempo que es adulado por sus riquezas y boato palaciegos.

En esta estrofa podemos apreciar también algunos rasgos que nos recuerdan al Villamediana más gongorino: la mencionada perífrasis mitológica y el empleo de términos cultistas que sirven para destacar el aludido ámbito de la corte: "áulicas", "pompas", "adulado". Puede observarse también cómo el empleo de los cultismos léxicos que se han mencionado y del cultismo sintáctico de los dos últimos versos de la estrofa, formando una construcción hiperbática, contribuyen a subrayar las miserias y engaños que se dan permanentemente en la corte, siendo la constante lisonjear y ser adulado siempre a través de la mentira y del engaño. A este mismo fin parece contribuir la aliteración de $a u$, sobre todo a la hora de asociar de forma paronomástica "áulicas" y "adulado", pues, a través de esa asociación fonética se acentúa la identificación entre el engaño y el palacio y, por extensión, la cortey el poder.

El poeta continúa, en el primer terceto, subrayando otro de los vicios que se dan en la corte, y del que se ha librado en su retiro espiritual, la lisonja que atenaza al cortesano y que le impide atender al sentido recto de la razón y, por tanto, desviarse de la virtud. El poeta en el primer verso, "Sirenas sean lisonja de su oído", alude a la mítica visión de las Sirenas que encantaban con sus cantos a los marineros cuyos barcos a la deriva terminaban por zozobrar en los escollos. Por ello, los sabios debían tapar sus oídos para no escuchar los encantos de su voz, como había recordado Séneca, Ad Lucilium Ep. XXXI, 2 (1971: 222): Ad summam sapiens eris, si cluseris aures, quibus ceram parum est obdere; firmiore spissamento opus est quam in sociis usum Vlixem ferunt. Illa vox, quae timebatur, erat blanda, non tamen publica, at haec, quae timenda est, non ex uno scopulo, sed ex omni terrarum parte circumsonat.

La imagen de las Sirenas gozaba de una gran tradición literaria, pues, ya en la Antigüedad clásica, había sido recreada, entre otros muchos, por Homero (Odisea XII, 1-200), Platón (República 617 B), Virgilio (Eneida V, 864), Ovidio (Metamorfosis V, 551-563), Plinio (Hist. Nat. X, 70), etc. Posteriormente, la leyenda de las Sirenas continuó cultivándose por otros mitógrafos que se convitieron en fuentes imprescindibles para todos los escritores, en general, y para los poetas áureos, en particular: G. Boccaccio, De Genealogie Deorum VII, 20, N. Conti, Mythologia, VII, 13, y, más cercano a nuestro poeta, J. Pérez de Moya, Filosofía secreta, Lib. II, cap. 14, arto X. La tópica imagen de las Sirenas se extendió también incluso por los dominios de la emblemática, ya que Alciato (1985: 152-153), en su emblema CXV, representó la legendaria figura de Ulises resistiendo al encantamiento de las Sirenas: 


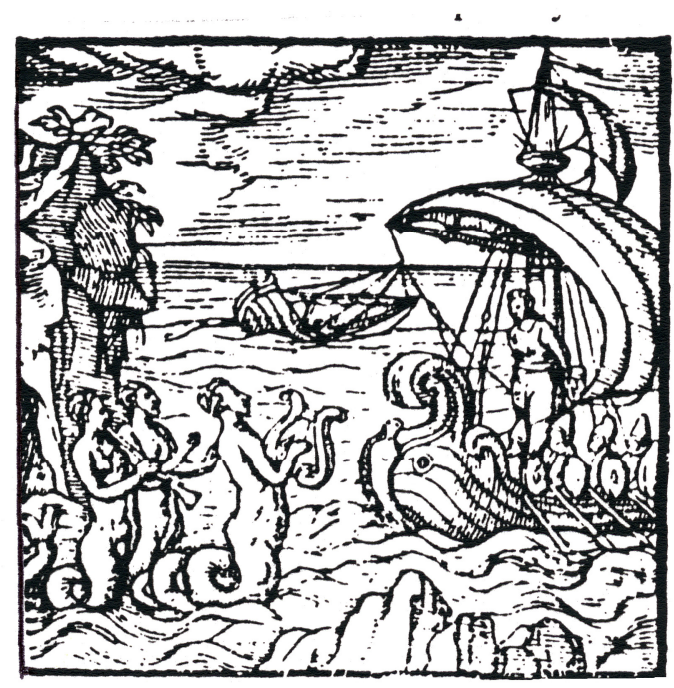

La recurrencia de Villamediana a esta mítica y emblemática historia de las Sirenas subraya, por lo tanto, el carácter moral del soneto, con el fin de enfatizar el reino del engaño que es la corte, esa "playa de sirenas" que dijera su íntimo amigo, don Luis de Góngora.

Con la referencia simbólica a las Sirenas, el poeta está contraponiendo en esta estrofa la inclinación de los cortesanos por las falsas apariencias, las insinceras adulaciones, los engaños, es decir, todo un repertorio de bajas pasiones que alejan al hombre del "mejor sentido", que no es otro que el de la razón. Debemos recordar cómo en esta época cartesiana, la razón es, en verdad, lo único que puede apartarnos del engaño de los sentidos. Por eso, las Sirenas, que son los falsos sentidos, las banalidades de las gloriae mundi, adulteran las claves de la razón y cierran al hombre su mejor sentido, es decir, que lo apartan de la virtud, que es el camino que debía seguir, como pedían los estoicos.

El poeta enfatiza el poder y seducción de las Sirenas, cuyo canto puede quedar simbolizado por la aliteración del sonido/s/ que se observa en el primer verso de la estrofa. También se puede apreciar cómo el poeta vuelve a emplear la aliteración de $a u$, que había usado en la estrofa anterior, con la palabra " $a \mathrm{~d} u$ lterando", con la que subraya el engaño que reina en la corte.

En la última estrofa el poeta vuelve a convertirse en el protagonista del poema, pues, como si al ejara el objetivo de su cámara de las miserias cortesanas y lo orientara hacia sí mismo, nos presenta su retiro natural y espiritual, como había hecho al principio en la primera estrofa. Así lo pone de manifiesto con el pronombre personal de primera persona, "Yo", que abre el terceto, y se nos muestra en la felicidad de su paraíso natural, en clara recreación del beatus ille horaciano: "entre estas mansas ondas, a las aves"; un paraje que, siguiendo el dictado de la tradición más genuinamente renacentista, queda quintaesenciado 
en la simple mención de esos elementos ('mansas ondas', 'tranquilas aguas', 'aves'). No interesa tanto la descripción o la ekfrasis paisajista, porque al poeta lo que realmente le importa es su "dulce quietud del ánimo" y la naturaleza es tan sólo el marco ideal en el que retirarse en soledad para estar consigo mismo. Además, la brevedad del cauce estrófico obligaba a caracterizar brevemente una naturaleza que debía cumplir su papel esencial como marco, pero un marco activo, pues, precisamente a esas aves -confiesa el poeta- deberá "desmentir" ("desvanecer y disipar alguna cosa para que no se conozca", Auts.) las "fatigas graves", las cargas o importantes sufrimientos.

La estrofa presenta claros ecos, entre otros, de Garcilaso de la Vega (Égloga II, 67-69):

\author{
y las aves $\sin$ dueño, \\ con canto no aprendido, \\ hinchen el aire de dulce armonía ${ }^{9}$
}

y de la oda primera de fray Luis de León ("Canción de la vida solitaria”, vv. 3135):

\author{
Despiértenme las aves \\ con su cantar sabroso no aprendido; \\ no los cuidados graves, \\ de que es siempre seguido \\ el que al ajeno arbitrio está atenido ${ }^{10}$.
}

Por otra parte, puede destacarse cómo el poeta emplea la aliteración de/s/y $/ n /$ a lo largo de la estrofa con el ánimo de simbolizar en el plano fonético el susurro de las aguas y el canto de las aves, de manera genérica, el murmullo de la naturaleza que le ha hecho olvidar o relativizar los sufrimientos que padecía por causas ajenas y que nada importan para la consecución de la "dulce quietud del ánimo" y "del mejor sentido" de "la razón", dela virtud.

Aunque, a medida que se ha ido comentando el poema, se han realizado las pertinentes observaciones de carácter estilístico que siempre deben estar absolutamente relacionadas con la explicación del tema o del contenido que se desarrolla en el texto, creo que no estaría de más ofrecer una reflexión valorativa sobre el estilo del soneto. El poeta, que es uno de los más conspicuos seguidores de su maestro y amigo, don Luis de Góngora, apenas sigue en esta composición los

${ }^{9}$ La cita textual de Garcilaso se hace por la edición que de su poesía ha preparado B. Morros (1995: 145).

${ }^{10}$ La cita textual de fray Luis de León se hace por la edición que de su poesía ha preparado G. Serés (1990: 54). El motivo puede verse ya en Propercio I 2,14: et volucres nulla dulcius arte canant. 
rasgos estilísticos que caracterizan la poesía de don Luis, sino que Villamediana, de acuerdo con la sobriedad y rigorismo del tema planteado, se decanta por una expresión poética que sigue más de cerca la huella de la sencillez y parquedad estilística propia de la tradición poética horaciana. Esto no quiere decir que no se haya localizado algún que otro rasgo que nos recordaría el quehacer expresivo de Góngora, como ocurre en el v. 4, en el que "aviso y no fatigas", parece inspirada en una de las fórmulas sintácticas que singularizarían la creación poética de don Luis: A y no B (Alonso 1950: 135ss.); o como sucede con la perífrasis mitológica con la que Villamediana aludía, en el v.5, al mito de Júpiter, transformado en lluvia de oro para amar a Dánae, y que le sirve para referirse metafóricamente al oro; y lo mismo cabría decir de la perífrasis mítica de las Sirenas para referirse metafóricamente, en los vv.9-11, a los engaños y las falsas adulaciones cortesanas.

Pero lo más notorio en este soneto del aventajado discípulo de Góngora es -como se ha dicho- la estrecha confabulación que el poeta establece entre su contenido y su expresión poética. Si el poeta subraya la felicidad que experimenta al haberse alejado del mundo de miserias cortesanas (ambiciones, engaños), y hallarse con su tranquilidad espiritual, despreocupado de las gloriae mundi, en un hermoso e idílico paisaje natural, era lógico que remarcase dicha experiencia ética con un discurso poético sencillo estilísticamente, con una sobria expresión literaria ajena a la cornucopia verbal gongorina. Por ello, resulta fácil hallar ecos de una poesía moral y rigorista como la de Medrano ("mal contentos", v.1) y fray Luis de León ("en canto ni adulado ni aprendido", v.13), o que bucee en las contenidas aguas de la expresión poética garcilasiana (v.13), de manera que su paisaje, por ejemplo, como en la obra del poeta del Tajo, se halla quintaesenciado, pero no descrito ("soledad", "mansas ondas", "aves").

En este mismo sentido, puede notarse cómo la expresión sintáctica queda contenida en cada una de las estrofas del soneto, que tienen también clara autonomía semántica. Frente a la habitual o frecuente expresión poética de los sonetos genuinamente gongorinos, cuyos catorce versos se alargaban descoyuntadamente en una única o, como mucho, dos oraciones, que se ramificaban, eso sí, en múltiples proposiciones subordinadas, aposiciones y todo ello en una hipertrófica e hiperbática expresión lingüística, ahora tenemos oportunidad de ver cómo el poeta acomoda la pureza y sencillez ideológica que proclama con la sobria y contenida, sencilla y pura expresión poética. Así, puede afirmarse que, como debe ser en poesía -y permítaseme el reduccionismo crítico de volver a la, por fin, superada división de los dos planos poéticos- el plano de la expresión es un fiel espejo de lo postulado en el plano del contenido.

Los teóricos y preceptistas del Siglo de Oro recomendaban que el soneto tratase un único concepto o un solo tema, como había formulado Francisco de Cascales en boca de Castalio: Sabido, pues, que el soneto por ser de especie lýrica es una composición grave y gallarda, conviene también saber que a de ser de un concepto. En todas las poesías es necessaria la unidad, pero en el soneto con vínculo más estrecho, por- 
que en essotras no se pide más que unidad de actión, y la actión encierra muchos y diversos conceptos. Mas el soneto, por ser poesía lýrica y tan corta, a de guardar unidad de concepto; digo que todo lo que el soneto abraçare se refiera a un solo concepto ${ }^{11}$.

El preceptista murciano volvería a ratificar la base conceptista del soneto en Ias Cartas filológicas (1961: III, 240). Y Luis Alfonso de Carvallo también confirma la unidad conceptual del soneto: En sonetos no se puede continuar materia larga, que cada concepto se ha de comprehender en un soneto, y un soneto no puede tener más de un concepto, y cada cuatro versos de los primeros se ha de concluir sentido perfecto, $y$ de los seis postreros a cada tres, se ha de acabar también cláusula. Por manera que todo el soneto se divida en cuatro puntos, uno al cuarto verso, otro al octavo, otro al onceno, otro al último. $Y$ en los seis postreros versos conviene estar toda la sustancia del soneto, y tener en sí algún concepto delicado, y que los ocho de antes vayan previniendo y haciendo la cama a lo que en estos seis postreros se dice ${ }^{12}$.

De acuerdo, pues, con lo que aconsejan los preceptistas y teóricos del Siglo de Oro, Villamediana, en este soneto, trata un único concepto o un solo tema, el beatus ille que experimenta el poeta alejado de las miserias cortesanas, una felicidad, por la tranquilidad espiritual, que surge en el ámbito de un solitario paraíso natural.

Pero el respeto y el sometimiento de Villamediana a lo preceptuado por los teóricos no se limita tan sólo al concepto desarrollado, sino que afecta también a la versificación y a la sintaxis o distribución de sus sentencias. Así, podemos comprobar cómo, en primer lugar, el poeta sigue la recomendación clásica de ofrecer un soneto con catorce versos endecasílabos, distribuidos en dos cuartetos y dos tercetos. Y por lo que se refiere a la rima, puede observarse cómo Villamediana sigue fielmente lo canonizado por Petrarca en su Canzoniere, es decir, mantiene inalterable la distribución de la rima en los cuartetos, de acuerdo con el tópico paradigma ABBA ABBA, y recrea uno de los esquemas petrarquistas más genuinos de la rima de los tercetos, CDC DCD. Y, en segundo lugar, la sintaxis y la distribución de las sentencias del soneto de Villamediana también reflejan fielmente las recomendaciones de los teóricos, pues -como puede observarsesus sentencias se dividen en cada uno de los cuatro puntos que había señalado Luis Alfonso de Carvallo, es decir, en los versos cuarto, octavo, undécimo y último.

Pero, a pesar de lo dicho, el soneto presenta, a mi juicio, una estructura que resulta un tanto peculiar, pues se aleja de las dos prácticas más frecuentes en el tratamiento del soneto en el Siglo de Oro; por una parte, no distribuye la materia poética planteando el asunto en los dos cuartetos y concluyéndolo en los dos

${ }^{11}$ Francisco de Cascales (1975: 251-252). También Díaz Rengifo, que consideraba el soneto como la más grave composición de la poesía española, había confirmado su unidad conceptuosa: "De ordinario no lleva sino un solo concepto, y éste dispuesto de tal manera, que no sobre, ni falte nada" (1977: 95).

${ }^{12}$ Luis Alfonso de Carvallo (1997: 217). Sobre el tema puede verse también Díez Echarri (1970: 244-249), García Berrio (1988: 446-451), Pérez-Abadín (1997: 29-48) y Costa (1998). 
tercetos, como era lo habitual en la poesía renacentista; $y$, por otra, tampoco nos ofrece un desarrollo continuado de principio a fin, como era lo más recurrente en la práctica sonetil en el siglo XVII, que se solía resolver en el segundo terceto, en los dos últimos versos, o en un verso final concluyente.

El soneto de Villamediana nos muestra lo que se podría considerar una estructura circular, pues el comienzo y el final nos remiten al mismo motivo, de manera que, cuando se acaba la lectura de la última estrofa, se vuelve a lo ya planteado en el primer cuarteto. Mientras que las dos estrofas centrales (el se gundo cuarteto y el primer terceto) también tienen el mismo motivo. Así, de forma más clara, podemos observar cómo en la primera y última estrofas el poeta habla de sí mismo en primera persona. Tras una generalizada proposición condicional en la que el poeta se plantea si hay un lugar sagrado para los descontentos, concreta su respuesta que su propia "dulce quietud del ánimo" sea su sagrario que se halla en "esta soledad"; el determinante esta nos permite situar el discurso del poeta en la propia esfera de la primera persona del pronombre.

De este modo, en el primer cuarteto, se puede apreciar cómo el poeta en primera persona ha planteado ya el asunto clave de la composición, que es el de su tranquilidad espiritual, en la grata soledad, donde la preocupación se centra en el aviso, en su formación virtuosa y no en las fatigas. La estrofa, por otra parte, mantiene, como ocurrirá en las tres restantes, una clara autonomía sintáctica y semántica, si bien es verdad que el soneto adquiere un sentido global y completo con la necesaria interdependencia de las cuatro estrofas.

En el segundo cuarteto, el poeta desvía el centro de interés de su yo a la tercera persona con el ánimo de ejemplificar las ambiciones cortesanas y los engaños que se dan al rededor del dinero, es decir, nos habla de los vicios y miserias humanas, las gloriae mundi, que él ha rechazado en su solitaria quietud espiritual. Ese cambio de enfoque en el planteamiento del tema le permite establecer un claro distanciamiento entre el camino y la situación personal elegida y la de todos aquellos que habitan en el tráfago cortesano. El cambio de perspectiva se pone de manifiesto con el uso de los verbos en tercera persona: "vea lograr", "Iisonjea".

El primer terceto refleja también otra muestra más del enjambre de miserias que es la corte y que se pone de manifiesto con la evocación de la conocida y legendaria historia de las Sirenas, convertidas por la tradición literaria y emblemática, desde la Antigüedad, en el gran símbolo de los engaños y falsas adulaciones que padecen todos los cortesanos. Ese ritmo de vida, dejándose arrastrar de las más viles pasiones que radican en las falsas apariencias, al ejan por completo al hombre de la verdadera razón, la virtud. Como la anterior estrofa, este terceto nos muestra otra de las fatigas graves que el poeta en su exilio natural no padece. De nuevo, el distanciamiento que el poeta pretende ofrecer, respecto de la primera estrofa, se hace explícito, como hizo en el último cuarteto, con el empleo de la tercera persona del plural, siendo las Sirenas el sujeto de los dos verbos: 'sean', 'cierren'. 
El contraste entre la primera y estas dos estrofas también se aprecia en el distinto uso temporal de los verbos: en el primer cuarteto el poeta emplea el verbo en presente de indicativo ('hay', 'granjea') -salvo 'sea' que aparece lógicamente en presente de subjuntivo por ser la apódosis de la proposición condicional- que nos remite al tiempo o momento presente en el que el poeta se halla; en las dos siguientes estrofas, puede comprobarse cómo el poeta ha empleado los tiempos en presente de subjuntivo, lo que contribuye a su deseo de distanciar esta realidad cortesana de la suya propia.

En el segundo terceto se puede observar cómo el poeta vuelve sobre sí mismo, incorporándose a través del 'Yo' que abre la estrofa y el uso del verbo en primera persona. De este modo, ya no muestra ninguna de las 'fatigas graves' que encadenan a los cortesanos, sino que ahora vuelve al tono planteado en el comienzo del soneto, es decir, que el poeta amplía la información con la que abrió el poema mostrándonos el paisaje quintaesenciado en el que habita y al que siempre deberá haberse liberado de las ambiciones y engaños de la Corte. El empleo del verbo en futuro imperfecto de indicativo pretende subrayar la eterna vinculación del poeta con el entorno solitario natural al que siempre le deberá haber encontrado el camino de la virtud.

Con esta vuelta al principio desde el final puede concluirse la estructura circular que ofrece el soneto, y el claro divorcio que se produce -perfectamente marcado en el poema- entre la feliz esfera privada, reflejada en el primer cuarteto y en el segundo terceto, y la viciosa parcela de las miserias de la corte, retratada en la segunda y tercera estrofas.

A modo de conclusión, creo conveniente terminar proponiendo una reflexión o una sugerencia acerca de la importancia que este soneto -y, en general, toda la poesía que conforma el Cancionero del desengaño- representa para la trayectoria poética del conde de Villamediana y, por extensión, para toda la poesía española del Siglo de Oro. A mi juicio, este soneto, junto con el restante corpus de textos que integran el Ilamado Cancionero del desengaño, mantienen un espíritu y un aliento común que acaba dándole unidad compositiva a la serie de poemas que lo integran, y que supone una apertura de la creación literaria de Villamediana hacia nuevos caminos poéticos, diferentes a los que ya había recorrido con anterioridad -como el de su poesía amorosa y mitológica-, que terminan por representar su más genuina creación poética.

Sin desmerecer ni infravalorar la significación ni la valía de su expresión poética, puede decirse que la poesía amorosa de Villamediana ha seguido la senda habitual de la inspiración petrarquista, del neoplatonismo o del amor cortés, con la consecuente retahíla de motivos, tópicos y procedimientos característicos de esas tradiciones que terminan embebiendo el acento personal de don Juan de Tassis en ese terreno de adocenamiento petrarquista. En el ámbito mitológico, Villamediana logró acercarse al magisterio poético que había iniciado su gran amigo, don Luis de Góngora, cuyo Polifemo abría la senda que debía seguir todo poema que pretendiera alcanzar el estilo heroico. Sobre todo su Fábula de 
Faetón eleva a Villamediana a lo más al to del Parnaso poético español, pero su voz poética continúa demasiado de cerca la estela de Góngora.

La traducción de la experiencia vital de Villamediana en materia poética ha supuesto que encuentre, sin duda, su voz más genuina y personal en todo el corpus poético en el que nos ofrece su interpretación moral del mundo: bien en su vertiente plebeya, con su poesía satírica -personal o política-, que lo convierte en el creador de la moderna poesía de protesta (Rozas 19802: 39-40), o bien en su discurso moral más grave. Si por un lado, desde la ladera popular, Villamediana ha orientado la creación poética a la senda de la poesía de protesta (que tantos frutos terminaría dando incluso en la etapa contemporánea), por otro, desde la orilla más culta, don Juan de Tassis ha logrado la creación de un Cancionero del desengaño, todo un corpus de poemas que ha conseguido hallar su unidad -en el sentido moderno e, incluso, actual- precisamente en la experiencia del destierro. A partir de entonces, ya no será el amor el sentimiento que termine hilvanando todos los poemas para tejer el cancionero literario, sino que ahora es otro nuevo sentimiento, el exilio, el que enhebra los fragmentos poéticos dispersos para terminar configurando un nuevo cancionero poético, que, lejos de estar tan triIlado como el petrarquista, resulta mucho más novedoso, aunque los precedentes literarios se remonten nada menos que a la Antigüedad clásica (Ovidio, H oracio, Séneca, Epicteto, etc.), o aunque haya tenido que reelaborar, para posibilitar esa nueva expresión poética, otros materiales literarios que no surgieron precisamente de los mismos dominios de la poesía exul, como la asimilación de la apartada poesía, entre otros, de fray Luis de León o, incluso, de don Luis de Góngora. Lo cierto es que su Cancionero del desengaño representa, a mi juicio, el mejor logro literario de Villamediana porque refleja la expresión poética más personal y distintiva de su excepcionalidad literaria, que le ha permitido, además, hacerse un hueco en el panorama poético español del Siglo de Oro, porque, quizás, nadie como él ha sabido crear un cancionero poético del exilio.

En este sentido, cabe señalar que Villamediana ha sabido abrir la creación poética española a nuevos senderos literarios porque está fundamentando con su propia obra la posibilidad de crear un cancionero poético que encuentra su justificación en la elaboración de un discurso ético que surge como fruto de su desengaño moral, derivado, a su vez, de la trágica experiencia del destierro. Esta aventura poética hal lará, además, una feliz expresión literaria en aquel los poetas que, por diferentes motivos, se vieron obligados a abandonar su patria, como fue el caso de Miguel de Barrios o Antonio Enríquez Gómez, entre otros, y que, en algún momento, también tradujeron esa experiencia vital en materia literaria que se destiló en la elaboración de cancioneros poéticos del destierro. De este modo, la poesía del Siglo de Oro español terminó encontrando nuevas posibilidades expresivas a raíz de una nefasta circunstancia o trágica experiencia vital que se convirtió en un tema literario o, si se quiere, en una forma de pensamiento, que se fue concretando en una materia poética que se fue destilando en un 
amplio muestrario de géneros y cauces poéticos, que, ocasionalmente, supuso la elaboración de un cancionero poético.

\section{Bibliografía}

Alciato, A. 1985. Emblemas, ed. de Santiago Sebastián, Madrid (Akal).

Alonso, Dámaso 1950. La lengua poética de Góngora (Parte primera, corregida), Madrid, Anejo XX dela R.F.E.

Bernat Vistarini, A. y Cull, J.T. 1999. Enciclopedia de emblemas españoles ilustrados, Madrid (Akal).

Blanco, M ercedes 1992. Les rhétoriques de la pointe. Baltasar Gracián et le conceptisme en Europe, Paris (Champion).

Carvallo, Luis Alfonso de 1997. Cisne de Apolo, ed. de A. Porqueras Mayo, Kassel (Reichenberger).

Cascales, Francisco de 1975. 1961. Cartas Filológicas, ed. de J. García Soriano, Madrid (Espasa-Calpe).

Cascales, Francisco de Tablas Poéticas, ed. de Benito Brancaforte, Madrid (Espasa-Calpe).

Costa, Angelina 1993. “Un sol eclipsado: la poesía de destierro del Conde de Villamediana”, en M. García Martín (ed.), Estado actual de los estudios sobre el Siglo de Oro, Salamanca (Ed. Universidad), pp.245-254.

Costa, Angelina 1998. "El legado renacentista en los sonetos de Góngora”, en J. Matas Caballero et alii, Actas del Congreso Internacional sobre Humanismo y Renacimiento, vol. II, León (Universidad), pp.27-37.

Cotarelo, Emilio 1886. El Conde de Villamediana. Estudio biográfico-crítico con varias poesías del mismo, Madrid (Sucesores de Rivadeneyra).

Díaz Rengifo, J. 1977. Arte Poética Española, ed. facs., Madrid (MEC).

Díez Echarri, Emiliano 1970. Teorías métricas del Siglo de Oro, Madrid (CSIC).

G arcía Berrio, Antonio 1988. Introducción a la poética clasicista. Comentario a las "Tablas Poéticas" de Cascales, Madrid (Taurus).

G arcilaso de la Vega 1995. Obra poética y textos en prosa, ed. de Bienvenido Morros, y est. Prel. de R. Lapesa, Barcelona (Crítica).

Guillén, Claudio 1998. Múltiples moradas. Ensayo de Literatura Comparada, BaceIona (Tusquets).

Herrera, Fernando de 2001. Anotaciones a la poesía de Garcilaso, ed. de I. Pepe y J.Mạ Reyes, Madrid (Cátedra).

León, fray Luis de 1990. Poesía completa, ed. de G. Serés, Madrid (Taurus).

M edrano, Francisco de 1988. Poesía, ed. de D. Alonso, Madrid (Cátedra).

M uñoz de San Pedro, V. 1946. “Un extremeño en la Corte de los Austrias Documentos inéditos sobre Don Rodrigo Cal derón, el Conde Duque de Olivares y el Conde de Villamediana)", Revista del Centro de Estudios Extremeños 2, 1946, 379-396. 
Orozco, Emilio 1988. Introducción al Barroco, ed. de José Lara Garrido, Granada (Universidad).

Pérez-A badín Barro, Soledad 1997. Los sonetos de Francisco de la Torre, Manchester (University).

Rivers, Elías L. 1993. El soneto español en el Siglo de Oro, Madrid (A kal).

Rosales, Luis 1966. El sentimiento del desengaño en la poesía barroca, Madrid (Cultura Hispánica).

Rosales, Luis 1969. Pasión y muerte del Conde de Villamediana, Madrid (Gredos).

Rozas, Juan Manuel 1964. El conde de Villamediana: Bibliografía y contribución al estudio de sus textos, Madrid (CSIC).

Rozas, Juan M anuel 1965. Cancionero de Mendes Britto. Poesías inéditas del conde de Villamediana, Madrid (CSIC).

R uiz, Pedro 1996. El espacio de la escritura. En torno a una poética del espacio del texto barroco, Bern (Peter Lang).

Séneca, L.A. 1971. Ad Lucilium Epistulae Morales, vol. III, London (Harvard University Press).

Villamediana, Conde de 19802. Obras, ed. de J.M. Rozas, Madrid (Castalia).

Villamediana, Conde de 1990. Poesía impresa completa, ed. de J.F. Ruiz Casanova, Madrid (Cátedra).

Villamediana, Conde de 1992. Poesía, ed. de Mạ.T. Ruestes, Barcelona (Planeta).

V ossler, Karl 1946. La poesía de la soledad en España, Buenos Aires (Losada). 